\title{
BMJ Open Exploring health literacy competencies towards patient education programme for Chinese-speaking healthcare professionals: a Delphi study
}

\author{
Li-Chun Chang, ${ }^{1}$ Yu-Chi Chen, ${ }^{2}$ Fei Ling Wu, ${ }^{1}$ Li-Ling Liao ${ }^{3}$
}

To cite: Chang L-C, Chen Y$\mathrm{C}$, Wu FL, et al. Exploring health literacy competencies towards patient education programme for Chinesespeaking healthcare professionals: a Delphi study. BMJ Open 2017;7:e011772. doi:10.1136/bmjopen-2016011772

- Prepublication history for this paper is available online. To view these files please visit the journal online (http://dx.doi.org/10.1136/ bmjopen-2016-011772).

Received 3 March 2016 Revised 2 September 2016 Accepted 8 September 2016

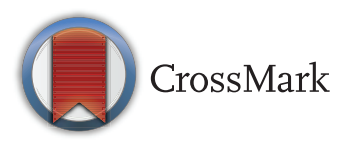

${ }^{1}$ School of Nursing, Chang Gung University of Science and Technology, Tao-Yuan, Taiwan

${ }^{2}$ Institute of Clinical Nursing, National Yang-Ming University, Taipei, Taiwan ${ }^{3}$ Department of Health Management, I-Shou University, Kaohsiung City, Taiwan

Correspondence to Li-Chun Chang; lichunc61@yahoo.com.tw

\section{ABSTRACT}

Objectives: To achieve consensus on a set of competencies in health literacy practice based on a literature review and expert consultation.

Setting: Hospitals and community health centres in Taiwan.

Method: A 2-stage modified Delphi study involving a literature review was conducted, followed by qualitative interviews and 3 rounds of email-based data collection over a 3-month period in 2011.

Participants: 15 Chinese healthcare practitioners with more than 6 months' experience in patient education were interviewed to collect data on health literacy practice. 24 experts (12 academic scholars in health literacy and 12 professionals with training related to health literacy practice) were invited to participate in the Delphi process.

Results: Qualitative data from the interviews were analysed and summarised to form 99 competency items for health literacy practice, which were categorised into 5 domains of health literacy practice including those pertaining to knowledge and skills. Consensus was reached on 92 of 99 competencies, using a modified Delphi technique.

Conclusions: The 92 competencies in health literacy practice embraced core components of patient education in the Chinese healthcare profession.

\section{INTRODUCTION}

Health literacy, as defined by the WHO, represents cognitive and social skills that determine the individual's motivation and ability to access, understand, and use information in ways that promote and maintain good health. ${ }^{1}$ To determine the contribution that health literacy makes to health disciplines, the rediscovery of health education should be explored in alliances between health and educational sectors in pursuing the goal of improved literacy levels in the population. ${ }^{2}$ Accordingly, investment in sustainable health education requires competent healthcare professionals who contribute

\section{Strengths and limitations of this study}

- To the best of our knowledge, this was the first study to develop a competency guide in health literacy practice for Chinese health professionals.

- These competencies embraced core components of patient education in healthcare.

- The main limitation of the study was that only 24 experts were recruited for the panel; however, we adopted subjective and objective methods to generate competencies in health literacy practice prior to achieving consensus in the Delphi process.

- Competencies in health literacy practice may provide a starting point for increased integration of health literacy concepts and skills into professional and continuing education programmes.

to the improvement of healthcare quality and reduce medical error. ${ }^{3}$

Health literacy practice involved the use of a set of patient-centred protocols and strategies to mitigate the effects of limited health literacy ${ }^{4}$ which should be considered in health education programmes. Healthcare providers' competencies in health literacy practice are vital in ensuring significant health outcomes through the efficiency of appropriate care plans. ${ }^{6}$ Healthcare professionals demonstrating assessment qualifications in their clinical practice could meet clients' care needs and could help design appropriate interventions to enhance selfcare abilities at a level that clients understand. ${ }^{7}$ However, previous studies have shown that healthcare providers overestimate patients' health literacy because of misunderstanding or limited cognition concerning health literacy.

Health literacy as an outcome of health education and its practices, which has been explored in previous studies, could be categorised into three groups: health literacy assessment $^{8}$ communication activities ${ }^{9}$ and 
educational strategies for patients with low health literacy (LHL) ${ }^{10}$ Although the importance of health literacy practice and use of a variety of health literacy techniques varied significantly across health disciplines, such as nutrition, nursing, and pharmacy, ${ }^{11}$ previous studies have demonstrated inadequate ability in health professionals with respect to limited recognition and awareness of health literacy, ${ }^{12}$ confidence ${ }^{9}$ and skills ${ }^{11}{ }^{13}$ in caring for those with LHL. It is important that health professionals possess adequate awareness, knowledge, skills, and attitudes when treating patients with LHL. ${ }^{4}$ Accordingly, identifying key elements of competencies in health literacy practice is an essential step in promoting the quality of care provided for individuals with LHL. ${ }^{14}$ In this study, we reviewed the literature to identify the core domains of health literacy practice and use it as a guideline in interviews designed to collect information regarding health professionals' competencies. The Delphi technique was used to establish consensus on the proposed competencies.

\section{METHODS}

A modified Delphi technique was used to achieve the aims of the study. The first round of the Delphi process was replaced by a literature review and face-to-face interviews designed to collect data regarding health literacy practice from clinical settings. This study was approved by the institutional review board at the institution with which the authors were affiliated.

\section{Identifying the key domains of competencies in health literacy practice}

We searched Medline, PsyclNFO, PubMed and OVID nursing collections for original studies and expert review papers concerning health literacy practice between 2005 and 2015. We entered 'health literacy' as the main keyword in the search to retrieve the relevant literature, and other related terms, such as training, teaching, practice, education and profession, were added with the Boolean operator 'AND' to refine our search. Only those literature on recommendations for health professionals related to health were included. However, articles which belonged to interviewing skills, cultural competency and motivational interviewing were generally not included.

\section{Qualitative interviews with healthcare professionals to generate competency items for health literacy practice}

The results of the literature review were used as interview guidelines to structure the interview framework. The recommended health literacy items identified through literature review were also confirmed in the interview process. The four interview questions included 'describe the attributes of patients who were difficult to teach', 'describe ways in which clients with LHL can be assisted', 'describe the way that assessments are conducted', and 'describe the communication techniques used in your patient education practice'.

First, two experienced health educators were recruited via referrals from hospital managers. Snowball sampling, also known as accidental sampling, was used to identify other suitable interviewees, and additional participants were introduced by the interviewees. After agreeing to participate, they engaged in recorded one-to-one interviews conducted by trained investigators. At this stage, 15 healthcare practitioners with more than 6 months' experience in patient education, including five nurses working in clinical, internal and surgical wards; four case managers; two health educators; three nutritionists; and a pharmacist, were interviewed between 27 September and 12 November 2011. Thirteen interviews were conducted at participants' offices at the hospital, and two interviews with health educators were conducted at community health centres; the interviews lasted between 60 and $90 \mathrm{~min}$. All interviews were conducted by authors with qualitative interview and health education experience. Moreover, the interview transcripts were analysed by the principle author, and the results were validated by all authors.

\section{Delphi process}

A Delphi process is defined as a multistage survey that ultimately attempts to achieve consensus on an important issue; its basic characteristics include anonymity, iteration, controlled feedback and statistical aggregation to create a group response. ${ }^{15}{ }^{16}$ Moreover, the method is highly recommended for issues that have not been explored in-depth and it is based on the premise that pooled intelligence enhances individual judgement and captured the opinions through an anonymous enquiry process. ${ }^{17}$ The questionnaire for the second round of data collection contained the results of the first round, mainly in the form of median or arithmetic mean values and distribution parameters. ${ }^{18}$

The first round of data collection was replaced by a literature review and face-to-face interviews to elicit the opinions of the expert panel. The second to fourth rounds involved questionnaires distributed via mail and followed the classic Delphi approach.

\section{Expert recruitment}

With respect to the sample size for the Delphi process, Parente and Anderson-Parente ${ }^{19}$ recommended a lower limit of 10 participants after the deduction of potential dropouts. In Taiwan, health literacy research has attracted academic and practical experts since 2008, and the majority of the health literacy literature has focused on patient factors. Since the number of experts with experience in health literacy research or practice was limited, we searched for Delphi technique experts from a list of professionals who had received a governmentfunded health literacy grant. In addition, we examined a list of professionals who had published research articles in the area. Approximately eight Delphi technique 
Table 1 The results of the literature review regarding health literacy practice in health professionals between 2005 and 2015

\begin{tabular}{lll}
\hline Themes in the literature & $\mathbf{n}(\%)$ & Source \\
\hline Assessment methods for low health literacy & $5(29.4)$ & $14,21-24$ \\
Appropriate written patient education materials or resources & $5(29.4)$ & $14,21,22,25,26$ \\
Communication strategies & $9(52.94)$ & $3,14,21,23-25,27-29$ \\
Understanding or knowledge of health literacy & $8(47.05)$ & $3^{2}, 12,14,22,{ }^{23}, 27,28,30$ \\
Association between literacy or health literacy and patient outcomes & $1(5.8)$ & 27 \\
Evaluating health literacy education & $2(11.7)$ & 31,32 \\
Teaching information and methods & $2(11.7)$ & 33,34 \\
Implementing a health literacy programme for patients & $2(11.7)$ & 12,33 \\
\hline
\end{tabular}

experts and recommended health professionals (who were trained in health literacy practice), were invited to participate in the study. Twenty-four experts (12 academic scholars in health literacy and 12 professionals with training related to health literacy practice) were invited to participate in the second to fourth rounds of data collection.

\section{Delphi procedure}

The modified Delphi method used in this study consisted of three rounds of email-based data collection, each of which lasted for 1 month during a 3-month period from January to April 2012. In each round, the experts were invited to rate the importance of each question using a five-point Likert-type scale ranging from 1 (not important) to 5 (very important) as the grading system. These individuals were aware that questions scored higher than 3 would be considered as important items. Group consensus was achieved if the criteria, including a mean and mode of at least 4.0 and a SD of $\leq 1$ were met. The quartile deviation was also provided to experts for consensus consideration in the Delphi process. Moreover, we also checked items that were ranked as 4 or greater on a Likert scale of $1-5$ by more than $80 \%$ of respondents in the final round.

The questionnaire contained space for an answer and feedback or further comments for each statement. In statements for which consensus was not achieved, feedback and comments were used to adjust the statement for the following round. The statements for all three rounds of the Delphi process were retained to ensure that they were all equally as likely to gain the highest importance rating and level of consensus. ${ }^{20}$ Experts were provided with feedback and a summary of the results of the previous round, and their individual modified and amended items were colour coded to prevent confusion during reading in the second and third rounds.

\section{RESULTS}

\section{Literature review}

Literature searches using the keywords 'training', 'teaching', 'competence' and 'profession' in combination with 'health literacy' produced 35, 35, 5 and 55 articles, respectively. A total of 106 articles were searched. After excluding duplicates $(n=14)$, anonymous authors $(n=6)$, non-English articles $(\mathrm{n}=6)$, and subjects that were not relevant to the health profession $(n=18), 62$ articles were relevant to the topic. Of these, 43 were discussion articles, and 19 were empirical studies, of which two were excluded, as the full text was not available. In the 17 complete articles, communication strategies $(\mathrm{n}=9$, $52.94 \%)$ and understanding health literacy knowledge $(\mathrm{n}=8,47.05 \%)$ were the most frequently mentioned health literacy practices. Assessment methods for LHL and appropriately written education materials or resources for patients were also crucial to health literacy practice. None of these studies or discussion articles were Chinese (table 1 ).

\section{Qualitative interview for health professionals}

The deductive content analysis described by Elo and Kyngäs ${ }^{35}$ was used to confirm four domains of health literacy practice, based on a review of related literature. In total, 648 meaningful statements were extracted from the interviews. Interview results were summarised as health literacy practices and used to compare categorisation results from the literature review for further classification. Thereafter, 99 meaning units were identified and classified into two domains with six subdomains including those pertaining to knowledge (ie, knowledge of health literacy and recognition of the characteristics of patients with LHL) and skills (ie, designing a patient education plan for patients with LHL, assessing health literacy assessment, adopting low-literacy health education strategies and evaluating an educational plan for patients with LHL attributes). In the analysis, 56 questions were derived from interviews, and 43 questions were selected from health literacy research publications.

\section{The consensus results of the Delphi process}

Twenty-four experts have completed each round of Delphi survey. In the second round, 10 of 99 items did not reach consensus, eight items had mean or mode scores between 3.5 and 4.0 with a SD of $>1$, and two items had mean or mode scores between 3.0 and 3.5. In the third round, none of the 99 items had a mean or mode score of $<3.0$, while 92 reached consensus with $80 \%$ agreement, four had mean scores between 3.5 and 
3.9 and three had scores of 4.0 with a SD of $>1$. Ultimately, in the final questionnaire, which was used in the fourth round and created according to experts' opinions, healthcare professionals' competencies in health literacy practice consisted of 92 consensus items, with seven items deleted (table 2).

\section{DISCUSSION}

In Taiwan and the rest of the world, most health literacy studies have focused on the patient's perspective. Only a few have explored health professionals' competencies in promoting patients' health literacy. Understanding health professionals' ability in health literacy practice is a basic step in establishing practice-based competencies. Delphi studies lack a consistent and well-defined standard for the application of group consensus. ${ }^{40}$ In addition to the predetermined levels of agreement mentioned in previous study, ${ }^{14}$ we used other consensus standards suggested by de Villers ${ }^{17}$ including the values of mean, SD and IQR to understand the level of consensus or lack thereof.

Although assessment of health literacy knowledge is an essential component of health literacy practices for health professionals, the result of our study has found that the measurement of health literacy knowledge could be either subjective or objective. The subjective measurement involved the participant's perceived knowledge of health literacy ${ }^{29}$ or the health literacy knowledge demonstrated by the participants. ${ }^{41}$ The objectives of assessment of health literacy knowledge performed in the current study was similar to that performed in the study conducted by Devraj $e t a l,{ }^{36}$ in which health literacy knowledge was designed in the form of test items that participants were required to answer to determine their health literacy levels. This could help in the evaluation of health literacy levels in untrained health professionals.

The items used in the current study were similar to those used in other studies, in that the assessment included the definition of health literacy, ${ }^{11}$ reading levels in patients with LHL, ${ }^{10}$ essential support for patients with LHL $^{23}$ and the consequences of LHL. ${ }^{38}$ Kripalani $e t a l^{23}$ Devraj $e t a l^{36}$ and Coleman et $a l^{14}$ classified the signs of LHL as knowledge items. For clearly differential conceptual knowledge or practical recognition of LHL, we grouped the signs of LHL confirmed during the interviews in the dimension of recognition of the attributes of patients with LHL. When health professionals adopted appropriate methods embedded health literacy competences to provide care for them, this attributes may not be the problems in healthcare settings. ${ }^{23}$ Undoubtedly, it is important for health professionals that they need to be aware of and recognise these signs when they conduct the assessment for patients.

The reason for this discrepancy could be that the study participants were physicians in 3 of the 17 studies and believed that health literacy was a communication skill. Coleman et $a l^{14}$ used the same five crucial domains to examine competencies in health literacy practice but divided the competencies into educational and practice domains. However, we incorporated a literature review and interviews into an educational process that aimed to meet the WHO's goals of promoting health literacy to the general public via educational systems. ${ }^{4}$ Extending the application of written or oral communication skills, as it relates to health literacy competencies in health education programmes, is critical to the improvement of public health literacy.

The competency items used in the current study were similar to those used in previous studies. However, because of differences in the first round of Delphi process and the Chinese descriptions in the practical narratives confirmed during the interviews, the meanings of the items somewhat differed from those provided by Coleman et al. ${ }^{14}$ The language differences could be considered as a study limitation. In the current study, we integrated the literature and interviews to produce the competencies of health literacy practice, which might be suitable for use with Chinese-speaking professionals.

It is worth noting that five of the seven questions for which a consensus could not be reached were interview items. These items were related to health education and captured via interview but have not been mentioned specifically in the health literacy literature; therefore, the experts could not reach consensus. The remaining two questions for which a consensus could not be reached were literature items. It is possible that, although the concepts originated from the literature, the experts considered the consent and health education materials analysed during the interviews duplicate information. K14 was a detailed description of LHL caused by communication barriers, which resulted from adverse effects on the patient's health, but it was also a repetition of $\mathrm{K} 6$.

Potential biases in traditional Delphi studies include the imposition of preconceptions on respondents and the use of poor techniques to summarise and present group responses. ${ }^{42}$ To avoid the drawbacks involving the imposition of preconceptions on respondents, a thorough review of the literature concerning the modified Delphi method was performed to collect information regarding competencies in health literacy practice, and qualitative interviews were conducted to confirm those generated by healthcare professionals in their own settings. This approach could increase the diversity of the item pool. Irrelevant or duplicate questions could be removed after the experts have reached a consensus.

\section{CONCLUSIONS}

The health literacy competencies identified in this study constitute an important and necessary step in the systematic design and evaluation of curricula required to produce a healthcare workforce that both accounts for and addresses the issues surrounding LHL. Most studies have suggested that health literacy and health education or communication skills are closely related. The present 


\section{Competency item}

ource

Final round

\section{Knowledge domain}

Knowledge of health literacy

K1. Health literacy refers only to a person's ability to read. (False)

$\mathrm{K} 2$. Adequate health literacy is the ability to read, understand, and process health information. (False)

K3. Those with low health literacy have poorer health outcomes relative to those with sufficient health literacy. (True)

$\mathrm{K} 4$. Age is a risk factor that decreases health literacy. (True)

K5. Patients with high educational levels may present with low health literacy. (True)

K6. Limited health literacy can produce barriers to clear, effective communication.

(True)

K7. Using an appropriate tool is the best way to assess health literacy and identify patients with low health literacy. (True)

K8. Individuals with high educational levels also need an easy method of learning

complicated health information. (True)

K9. The general rule is to write consent documents at a 7 th-grade reading level. (True)

K10. Suitable educational materials designed for people with low literacy should be understandable at levels below the 6th grade in elementary school. (True)

K11. People with low health literacy need extra medical support and therefore have higher healthcare costs. (True)

K12. Health education materials should be written at or below a 7th-grade reading

level. (True)

K13. Health literacy could affect physician-patient communication. (True)

K14. Persons with low health literacy experience limited comprehension of health

information, leading to care problems. (True)

Recognition of attributes of patients with low health literacy (If you agree the attributes

of LHL listed in following items, please marked $\checkmark$ in the box.)

Patients with low health literacy...

A1. May pretend to understand what the health educator says and ask for help at home. $\square$

A2. Will say, 'I can do this, there is no need to teach me' to cover up for their lack of understanding. $\square$

A3. Will repeat the same questions. $\square$

A4. Will not tell you if they cannot read. $\square$

A5. Are more likely to misinterpret medication instructions provided on prescription

labels. $\square$

A6. Will easily misunderstand prescription instructions. $\square$

A7. Cannot understand medication indications. $\square$

Devraj et $a{ }^{\beta 6}$

Devraj et a ${ }^{\beta 6}$

Institute of

Medicine ${ }^{4}$

Devraj et $a^{\beta 6}$

Interview

Schwartzberg

et $a l^{11}$

Institute of

Medicine $^{4}$

Interview

Institute of

Medicine $^{4}$

Institute of

Medicine ${ }^{4}$

Weiss and

Palmer ${ }^{37}$

Institute of

Medicine ${ }^{4}$

Schwartzberg

et $a l^{11}$

Institute of

Medicine ${ }^{4}$

Interview

Interview

Interview

Devraj et $a^{\beta 6}$

Devraj et a/ ${ }^{\beta 6}$

Devraj et $a \beta^{\beta 6}$ Kripalani et a ${ }^{33}$

Roundaccepted

Percentage of

Mean Mode

$\geq 4$

83.3

91.7

$\begin{array}{ll}1.0 & 0.5\end{array}$

2

4.3

$0.7 \quad 0.5$

2

87.5

83.3

87.5

87.5

83.3

83.3

83.3

54.2

87.5

83.3

87.5

$4.0 \quad 4$

$0.7 \quad 0.5$

$\begin{array}{llll}4.7 & 5 & 0.7 & 0.3\end{array}$

$\begin{array}{llll}4.7 & 5 & 0.7 & 0.3 \\ 4.7 & 5 & 0.7 & 0.3\end{array}$

$\begin{array}{llll}4.2 & 5 & 1.0 & 0.8\end{array}$

$\begin{array}{llll}4.3 & 5 & 1.0 & 0.8\end{array}$

$\begin{array}{llll}4.0 & 4 & 1.0 & 1.0\end{array}$

Delete

3.83

$1.1 \quad 1.0$

2

2

2

87.5

Delete

54.2

$4.4 \quad 5$

$0.9 \quad 0.8$

$\begin{array}{llll}4.0 & 4 & 1.0 & 1.0\end{array}$

$\begin{array}{llll}4.7 & 5 & 0.7 & 0.3\end{array}$

$\begin{array}{llll}3.4 & 4 & 1.3 & 1.0\end{array}$

जा 


\section{Competency item}

A8. Will often bring family members along when talking to healthcare professionals. A9. Will make excuses to avoid reading health information materials when given material to read. $\square$

A10. Often report about their medicine.

A11. Only seek assistance when symptoms worsen. $\square$

A12. Cannot understand medical forms and are therefore unable to complete them accurately. $\square$

A13. Are likely to put a lot of folded paper in their pockets or wallets. $\square$

A14. Do not make necessary appointments or attend follow-up.

A15. May be likely to pose few questions to professionals.

A16. Cannot talk about how to take medicine.

Skill domain

Designing a health education plan for patients with low health literacy

D1. Handle the psychical barriers to conducting health behaviours for clients

D2. Cooperate with other professionals to design health education plans

D3. Design audiovisual teaching materials

D4. Have the language ability to handle different patients

D5. Provide group health education

D6. Implement behaviour modification counselling

D7. Design computer-based teaching aids

D8. Design health education flyers with $<20 \%$ text

D9. Apply appropriate education theories in the curriculum

D10. Establish a personal profile of teaching materials

D11. Design a teaching plan for multicultural populations

D12. Design education materials for illiterate individuals

Assessing health literacy for patients with low health literacy

Interview

As1. Determine the right teaching time for various clients

As2. Determine potential education barriers based on patient characteristics

As3. Apply appropriate tools to assess patient health literacy levels

As4. Conduct health assessments by collecting personal, organisational, and community data

As5. Identify the classical attributes of low health literacy prior to teaching

Adopting low-literacy health education strategies

$\mathrm{S} 1$. Use plain language instead of medical jargon

S2. Use storytelling to make clients understand

S3. Use metaphors to explain the disease to clients

S4. Use life-oriented examples to explain the care that patients need

\section{Source}

Devraj et a

Kripalani et af

Devraj et $a \beta^{\beta 6}$

Jukkala et $a \beta^{\beta 8}$

Institute of

Medicine $^{4}$

Kripalani et $a^{23}$

Institute of

Medicine

Interview

Kripalani et $a^{23}$

2

Roun

undaccepted

Final round

\section{Percentage of}

$\geq 4$

$\begin{array}{lllll}83.3 & 4.4 & 5 & 1.0 & 0.5\end{array}$

$\begin{array}{lllll}83.3 & 4.4 & 5 & 1.0 & 0.5 \\ 87.5 & 4.4 & 5 & 0.7 & 0.5\end{array}$

87.5

87.5

87.5

$\begin{array}{llll}4.4 & 5 & 0.7 & 0.5\end{array}$

2

87.5

83.3

87.5

83.3

87.5

$4.7 \quad 5$

$0.7 \quad 0.3$

Interview

Interview

Interview

Interview

Interview

Interview

Interview

Interview

Interview

Interview

Interview

Interview

Interview

Interview

Institute of

Medicine $^{4}$

Institute of

Medicine $^{4}$

Kripalani et $a^{23}$

Kripalani et $a^{p^{3}}$

Kripalani et $a^{23}$

Kripalani et $a^{\text {f3 }^{3}}$

Interview

2

2

2

2

2

2

2

2

2

2
2

2

2

2

\section{2}

2

2

2

2

2

2

2
2
87.5

87.5
87.5

87.5

87.5

79.2

83.3

83.3

83.3

83.3

87.5

87.5

83.3

87.5

83.3

83.3

87.5

87.5

87.5

87.5

87.5

83.3

$\begin{array}{ll}4.7 & 5\end{array}$

$\begin{array}{lll}0.7 & 0.3\end{array}$

$\begin{array}{ll}0.8 & 0.8\end{array}$

$\begin{array}{ll}0.7 & 0.5\end{array}$

$\begin{array}{ll}0.9 & 0.8\end{array}$

$\begin{array}{ll}0.8 & 0.8\end{array}$

$\begin{array}{ll}4.4 & 5 \\ 4.1 & 4\end{array}$

$\begin{array}{ll}0.7 & 0.5\end{array}$

$0.7 \quad 0.3$

$\begin{array}{ll}0.7 & 0.3\end{array}$

$\begin{array}{ll}0.7 & 0.5\end{array}$

1.10 .5

$1.0 \quad 0.5$

$\begin{array}{ll}1.0 & 0.3\end{array}$

$\begin{array}{ll}1.0 & 0.5\end{array}$

$\begin{array}{ll}1.0 & 0.0\end{array}$

$\begin{array}{ll}0.7 & 0.3\end{array}$

$0.7 \quad 0.5$

$\begin{array}{ll}1.0 & 0.5\end{array}$

$4.6 \quad 5$

$4.4 \quad 5$

\begin{tabular}{|c|c|c|c|}
\hline 4.7 & 5 & 0.7 & 0.3 \\
\hline 4.7 & 5 & 1.0 & 0.0 \\
\hline 4.7 & 5 & 1.0 & 0.0 \\
\hline 8 & 5 & 0.7 & 0.0 \\
\hline 8 & 5 & 0.7 & 0.0 \\
\hline 4.8 & 5 & 0.7 & 0.0 \\
\hline 7 & 5 & 0.7 & 0.3 \\
\hline .7 & 5 & 0.7 & 0.3 \\
\hline 4 & 5 & 1.0 & 0. \\
\hline
\end{tabular}


Final round

S5. Teach using language the student understands

S6. Explain health education using materials available to the patient

S7. Connect new learning with previous experience

S8. Limiting curricula to 2 or 3 new topics

S9. Use the teach-back technique

S10. Teach repeatedly when clients cannot understand the teaching content

S11. Teach difficult materials repeatedly

S12. Use the demonstrate-do technique

S13. Provide health education materials and encourage clients to discuss them with

their families

S14. Provide health education materials with 'questions and answers'

S15. Use simple words to explain care plans and related treatment

S16. Base decisions regarding teaching focus on treatment progress

S17. Summarise the key points of teaching at the end of the interview

S18. Instruct others in the creation of a care plan rather than explaining the disease or

condition

S19. Use pictorial methods, rather than words, to emphasise importance of issues for clients

S20. Provide self-designed sticks to allow clients to mark their records

S21. Use the one-by-one method and pictorial image material

S22. Use media to benefit teaching outcomes

S23. Design teaching materials as teaching aids in health education

S24. Use online or internet teaching

S25. Consider disobedient behaviour to be temperate coping behaviour

S26. Offer more encouragement to patients and illiterate clients

S27. Understand clients' disobedient behaviours

S28. Invite caregivers to participate in the teaching plan

S29. Encourage clients and their families and clarify unclear parts of teaching via

telephone

S30. Present oneself to clients as a resource

S31. Create an environment of mutual trust
Interview

Interview

Interview

Schwartzberg

et al

Kripalani et $a^{R^{3}}$

Williams et $a^{\beta 9}$

Interview

Interview

Interview

Interview

Schwartzberg

et $a l^{11}$

Interview

Kripalani et $a^{23}$

Interview

Kripalani et $a^{23}$

Interview

Interview

Interview

Interview

Interview

Interview

Interview

Interview

Interview

Interview

Interview

Institute of

Medicine

Interview

Institute of

Medicine $^{4}$

Interview

Interview

\section{Percentage of}

Roundaccepted $\geq 4$

83.3

83.3

83.3

83.3

83.3

83.3

50

83.3

87.5

83.3

87.5

83.3

87.5

95.8

83.3

87.5

87.5

83.3

83.3

83.3

83.3

83.3

87.5

83.3

87.5

87.5

87.5

$\begin{array}{llll}4.7 & 5 & 1.0 & 0.0\end{array}$

$\begin{array}{llll}4.7 & 5 & 1.0 & 0.0\end{array}$

$\begin{array}{ll}1.0 & 0.0 \\ 1.0 & 0.0\end{array}$

S32. Encourage sharing between clients

S33. Create an embarrassment-free environment

S34. Ensure clients' confidentiality

S35. Encourage clients to take notes during interviews 


\section{Competency item}

S36. Teach clients to ask, 'What is my main problem?'

S37. Teach clients to ask, 'What do I need to do?'

S38. Teach clients to ask, 'What can I do to help my body?'

S39. Encourage clients to use the question-posing method

S40. Encourage clients to talk about what doctors say to them

S41. Encourage clients to demonstrate learnt skills to determine their understanding

S42. Ask clients to provide evidence of their health behaviour

S43. Make eye contact with patients to ensure concentration

S44. Ask clients to restate the key points that they have learnt

S45. Pay attention to questions that patients ask repeatedly

S46. Pay attention to non-verbal (eg, facial) expressions to determine whether the

patient has understood

Evaluating an educational plan for patients with low health literacy

E1. Build up the right evaluation criteria for health literacy practice

E2. Conduct appropriate evaluations to demonstrate the effectiveness of health literacy

practice

E3. Modify education plans to fit patients' problems

E4. Illustrate the appropriate effectiveness of teaching based on health literacy

E5. Encourage clients with low health literacy to share the successful action outcome

E6. Design various evaluation approaches according to clients' health literacy levels

${ }^{*}$ Reverse item.

A: recognition of attributes of patients with low health literacy; As: assessing health literacy for low health literate patients; D: designing a health education plan for patients with low health literacy; E: evaluating an educational plan for patients with low health literacy; K: knowledge of health literacy; S: adopting low-literacy health education strategies.

QD, Quartile Deviation. 
study applied these education principles in a holistic and continuous process to construct an index for assessing practice competencies.

A modified Delphi technique was used to achieve consensus on health literacy competencies for Chinesespeaking healthcare professionals. Further empirical studies are required to validate whether the 92 items identified can be grouped into the six domains of competencies in health literacy practice. Moreover, further work is required to prioritise these 92 items, and educational research is required to validate the competencies in health literacy practice and determine which should be taught, which healthcare professionals should receive training, which settings should be used and which teaching methods should be adopted to improve patientcentred outcomes.

Acknowledgements The authors would like to thank the experts and interviewees involved in the study. They also appreciate the helpful comments received from the anonymous reviewers at BMJ Open.

Contributors Y-CC, FLW and L-CC conducted the qualitative interviews. L-LL and L-CC analysed the interview and Delphi data. L-CC wrote the manuscript. All authors critically revised and approved the final manuscript.

Funding This project was funded by the Ministry of Science and Technology, Taiwan (NSC 100-2511-S-255-001-MY2), and financial assistance was received from Chang Gung Memorial Hospital (BMRP 978).

Competing interests None declared.

Patient consent Obtained.

Ethics approval Chang Gung Memorial Hospital.

Provenance and peer review Not commissioned; externally peer reviewed.

Data sharing statement Additional data can be accessed via the Dryad data repository at http://datadryad.org/ with the doi:10.5061/dryad.86t23.

Open Access This is an Open Access article distributed in accordance with the Creative Commons Attribution Non Commercial (CC BY-NC 4.0) license, which permits others to distribute, remix, adapt, build upon this work noncommercially, and license their derivative works on different terms, provided the original work is properly cited and the use is non-commercial. See: http:// creativecommons.org/licenses/by-nc/4.0/

\section{REFERENCES}

1. Nutbeam D. Health promotion glossary. Health Promot 1986;1:113-27.

2. Nutbeam $D$. Health literacy as a public health goal: a challenge for contemporary health education and communication strategies into the 21st century. Health Promot Int 2000;15:259-67.

3. Coleman CA, Fromer A. A health literacy training intervention for physicians and other health professionals. Fam Med 2015;47:388-92.

4. Institute of Medicine Committee on Health Literacy. In: Nielsen-Bohlman L, Panzer AM, Kindig DA, eds. Health literacy: a prescription to end confusion. What is health literacy. Washington DC: National Academies Press (US). Copyright 2004 by the National Academy of Sciences. All rights reserved, 2004:31-57.

5. Estacio EV, McKinley RK, Saidy-Khan S, et al. Health literacy: why it matters to South Asian men with diabetes. Prim Health Care Res Dev 2014:1-5.

6. Atcherson SR, Zraick RI, Hadden K. A need for health literacy curriculum: knowledge of health literacy among U.S. audiologists and speech-language pathologists in Arkansas. Educ Health (Abingdon) 2013;26:85-8.

7. Smith DL, Gutman SA. Health literacy in occupational therapy practice and research. Am J Occup Ther 2011;65:367-9.

8. Dickens $\mathrm{C}$, Lambert BL, Cromwell T, et al. Nurse overestimation of patients' health literacy. J Health Commun 2013;18(Supp1 1):62-9.
9. Ali NK, Ferguson RP, Mitha S, et al. Do medical trainees feel confident communicating with low health literacy patients? J Community Hosp Intern Med Perspect 2014;4:22893. doi:10.3402/ jchimp.v4.22893

10. Cafiero M. Nurse practitioners' knowledge, experience, and intention to use health literacy strategies in clinical practice. $J$ Health Commun 2013;18(Supp1 1):70-81.

11. Schwartzberg JG, Cowett A, VanGeest J, et al. Communication techniques for patients with low health literacy: a survey of physicians, nurses, and pharmacists. Am J Health Behav 2007;31 (Suppl 1):S96-104.

12. Macabasco-O'Connell A, Fry-Bowers EK. Knowledge and perceptions of health literacy among nursing professionals. $J$ Health Commun 2011;16(Suppl 3):295-307.

13. Seligman HK, Wang FF, Palacios JL, et al. Physician notification of their diabetes patients' limited health literacy. A randomized, controlled trial. J Gen Intern Med 2005;20:1001-7.

14. Coleman CA, Hudson S, Maine LL. Health literacy practices and educational competencies for health professionals: a consensus study. J Health Commun 2013;18(Suppl 1):82-102.

15. Linstone $\mathrm{H}$, Turoff $\mathrm{M}$. The Delphi method: techniques and applications. Reading, PA: Addison-Wesley, 1975.

16. Keeney $S$, Hasson F, McKenna $H$ (eds). Conducting the research using the Delphi technique. In: The Delphi technique in nursing and health research. Wiley-Blackwell, 2011:69-83.

17. de Villiers MR, de Villiers PJ, Kent AP. The Delphi technique in health sciences education research. Med Teach 2005;27:639-43.

18. Bogner A. Interviewing experts. England: Palgrave Macmillan, 2009.

19. Parente FJ, Anderson-Parente JK. Delphi inquiry systems. In: Wright G, Ayton P, eds. Judgemental forecasting. Chichester: John Wiley, 1987:77-86.

20. Keeney S, Hasson F, McKenna H (eds). Analysing data from a Delphi and reporting results. In: The Delphi technique in nursing and health research. Wiley-Blackwell, 2011:84-95.

21. Toronto CE, Weatherford B. Health literacy education in health professions schools: an integrative review. J Nurs Educ 2015;54:669-76.

22. Lambert M, Luke J, Downey B, et al. Health literacy: health professionals? Understandings and their perceptions of barriers that Indigenous patients encounter. BMC Health Serv Res 2014;29:614.

23. Kripalani S, Jacobson KL, Brown S, et al. Development and implementation of a health literacy training program for medical residents. Med Educ Online 2006;11:1-8.

24. Maniaci MJ, Heckman MG, Dawson NL. Functional health literacy and understanding of medications at discharge. Mayo Clin Proc 2008;83:554-8.

25. Callahan LF, Hawk V, Rudd R, et al. Adaptation of the health literacy universal precautions toolkit for rheumatology and cardiologyapplications for pharmacy professionals to improve self-management and outcomes in patients with chronic disease. Res Social Adm Pharm 2013;9:597-608.

26. Broussard B, Radkins JB, Compton MT. Developing visually based, low-literacy health education tools for African Americans with psychotic disorders and their families. Community Ment Health $J$ 2014;50:629-36.

27. Coleman CA, Appy S. Health literacy teaching in US medical schools, 2010. Fam Med 2012;44:504-7.

28. Green JA, Gonzaga AM, Cohen ED, et al. Addressing health literacy through clear health communication: a training program for internal medicine residents. Patient Educ Couns 2014;95:76-82.

29. Mackert M, Ball J, Lopez N. Health literacy awareness training for healthcare workers: improving knowledge and intentions to use clear communication techniques. Patient Educ Couns 2011;85:e225-8.

30. Mackert M. Health literacy knowledge among direct-to-consumer pharmaceutical advertising professionals. Health Commun 2011;26:525-33.

31. Primack BA, Wickett DJ, Kraemer KL, et al. Teaching health literacy using popular television programming: a qualitative pilot study. Am J Health Educ 2010:41:147-54.

32. Price-Haywood EG, Harden-Barrios J, Cooper LA. Comparative effectiveness of audit-feedback versus additional physician communication training to improve cancer screening for patients with limited health literacy. J Gen Intern Med 2014;29:1113-21.

33. Levasseur M, Carrier A. Do rehabilitation professionals need to consider their clients' health literacy for effective practice? Clin Rehabil 2010;24:756-65.

34. Zanchetta MS, Maheu C, Fontaine C, et al. Awakening professionals critical awareness of health literacy issues within a francophone linguisticminority population in Ontario. Chronic Dis Inj Can 2014;34:236.

35. Elo $\mathrm{S}$, Kyngäs $\mathrm{H}$. The qualitative content analysis process. J Adv Nurs 2008;62:107-15. 
36. Devraj R, Butler LM, Gupchup GV, et al. Active-learning strategies to develop health literacy knowledge and skills. Am J Pharm Educ 2010;74:137-45.

37. Weiss BD, Palmer R. Relationship between health care costs and very low literacy skills in a medically needy and indigent Medicaid population. J Am Board Fam Pract 2004;17:44-7.

38. Jukkala A, Deupree JP, Graham S. Knowledge of limited health literacy at an academic health center. J Contin Educ Nurs 2009;40:298-302; quiz 03-4, 36.
39. Williams MV, Davis T, Parker RM, et al. The role of health literacy in patient-physician communication. Fam Med 2002;34:383-9.

40. Williams PL, Webb C. The Delphi technique: a methodological discussion. J Adv Nurs 1994;19:180-6.

41. $\mathrm{Ha} \mathrm{H}$, Lopez $\mathrm{T}$. Developing health literacy knowledge and skills through case-based learning. Am J Pharm Educ 2014;78:17.

42. Keeney S, Hasson F, McKenna H (eds). Ethical considerations. In: The Delphi technique in nursing and health research. Wiley-Blackwell, 2011:105-13. 